\title{
Protective effects of Ursolic acid and Luteolin against oxidative DNA damage include enhancement of DNA repair in Caco-2 cells.
}

Authors: Alice A. Ramos ${ }^{1,2}$, Cristina Pereira-Wilson ${ }^{2, *}$, Andrew R. Collins ${ }^{1}$

${ }^{1}$ Department of Nutrition, University of Oslo, Norway

${ }^{2}$ CBMA-Centre of Molecular and Environmental Biology/Department of Biology, School of Sciences, University of Minho, 4710-057 Braga, Portugal

Corresponding author: $*$ Tel.: +351253604318; fax: +351253678980; e-mail address: cpereira.bio.uminho.pt (C. Pereira-Wilson) 


\section{Abstract}

28 Consumption of fruits and vegetables is associated with a reduced risk of developing a wide range of cancers including colon cancer. In this study, we evaluated the effects of two compounds present in fruits and vegetables, ursolic acid, a triterpenoid, and

31 luteolin, a flavonoid, on DNA protection and DNA repair in Caco-2 cells using the

32 comet assay.

33 Ursolic acid and luteolin showed a protective effect against $\mathrm{H}_{2} \mathrm{O}_{2}$-induced DNA

34 damage. To evaluate effects on induction of base oxidation, we exposed cells to the 35 photosensitiser Ro 19-8022 plus visible light to induce 8-oxoguanine. Luteolin 36 protected against this damage in Caco-2 cells after a short period of incubation. Repair 37 rate was increased by pre-treatment of cells for $24 \mathrm{~h}$ with ursolic acid or luteolin 38 (rejoining of strand breaks) in Caco-2 cells after treatment with $\mathrm{H}_{2} \mathrm{O}_{2}$. We also 39 measured the incision activity of a cell extract from Caco- 2 cells treated for $24 \mathrm{~h}$ with

40 test compounds on a DNA substrate containing specific damage (8-oxoGua), to evaluate 41 effects on base excision repair activity. Preincubation for $24 \mathrm{~h}$ with ursolic acid 42 enhanced incision activity in Caco-2 cells. In conclusion, we demonstrated for the first 43 time that ursolic acid and luteolin not only protect DNA from oxidative damage but also 44 increase repair activity in Caco-2 cells. These effects of ursolic acid and luteolin may 45 contribute to their anti-carcinogenic effects.

48 Keywords: ursolic acid; luteolin; DNA oxidation; antioxidants; DNA repair; comet 49 assay. 


\section{Introduction}

52 Colorectal cancer (CRC) is one of the main causes of cancer-related mortality in the

53 western world and was the second most common cancer in Europe in 2006 [1].

54 Oxidative stress, defined as a disturbance in the equilibrium status of pro-oxidant and antioxidant systems in favour of pro-oxidant, can damage diverse cellular macromolecules such as DNA, lipids, and proteins. The various types of DNA damage that can be generated as a result of oxidative attack, if not properly removed, can lead to mutagenesis and/or cell death. 8-oxo-7,8-dihydroguanine (8-oxoGua) is one of the most abundant forms of DNA oxidation and can cause $\mathrm{G}$ to $\mathrm{T}$ transversions in several oncogenes and tumour suppressor genes [2]. The major mechanism repairing DNA oxidation damage is the base excision repair (BER) pathway. In BER, DNA glycosylases are responsible for cleavage of the $N$-glycosidic bond between the base and the pentose sugar, removing modified DNA bases and creating an apurinic or apyrimidinic site (AP site). Endonucleolytic activity of the glycosylases or an APendonuclease transforms AP sites to gaps in DNA that are filled by a DNA polymerase and sealed by a DNA ligase $[3,4]$. In the present study we have evaluated effects of two phytochemicals found in fruits, vegetables and spices on DNA oxidation and DNA repair.

Accumulating evidence from epidemiological studies as well as laboratory data suggest that consumption of fruits and vegetables is associated with a reduced risk of developing a wide range of cancers including colon cancer [5,6]. Dietary strategies for cancer prevention are considered attractive alternatives because the consumption of natural compounds with potential chemopreventive effects is associated with low toxicity, safety and good acceptance by the public $[7,8]$.

Ursolic acid (UA), a natural pentacyclic triterpenoid acid, is widespread in nature and abundant in certain medicinal plants. UA has been reported to possess a wide range of biological activities, such as anti-inflammatory, anticarcinogenic, antihyperglycemic, hepatoprotective and neuroprotective activities [9-12].

Luteolin (Lut) is a flavons, a subclass of flavonoids, found in fairly large amounts in

80 fruits, vegetables, olive oil, red wine and tea. Many studies have shown that Lut exhibits

81 a variety of pharmacological activities, including anti-inflammatory, antibacterial, 
antioxidant and anticancer activities [13-16]. Contrarily to Lut, UA is not an antioxidant at relevant cellular redox conditions.

Protection of DNA from damage and modulation of DNA repair enzyme capacities may be assumed to contribute to protection against mutations and to maintenance of genomic stability. In the current study we evaluated DNA-protective and repair-enhancing effects of Lut and UA in human colon cells (Caco-2) exposed to oxidative agents. DNA damage was evaluated by alkaline single-cell gel electrophoresis (comet assay). BER of oxidised DNA was measured using an in vitro assay for incision activity of a cell extract, incubated with a substrate containing oxidised DNA bases [17]. We also assessed the ability of cells to rejoin strand breaks induced in DNA by $\mathrm{H}_{2} \mathrm{O}_{2}$. UA and Lut were used in concentrations likely to be attained in gut when humans have a diet rich in fruits and vegetables.

\section{Material and methods}

\subsection{Chemicals}

UA (purity $\geq 90 \%$ ), hydrogen peroxide, Dulbecco's Modified Eagle Medium (DMEM), penicillin/streptomycin, trypsin solution and 3-(4,5-dimethylthiazole-2-yl)-2,5-diphenyl tetrazolium bromide (MTT) was purchased from Sigma-Aldrich (St. Louis, MO, USA). Lut (purity > 90\%) was from Extrasynthese (Genay, France). Fetal bovine serum (FBS) was purchased from Biochrom KG (Berlin, Germany). Ro (photosensitizer Ro19-8022) was from F.Hoffmann-La Roche (Basel, Switzerland). SYBR Gold (nucleic acid gel stain) was from Invitrogen Molecular probes (Oregon, USA). All other reagents and chemicals used were of analytical grade.

\subsection{Cell culture}

Caco-2 cells (derived from human colon carcinoma) were maintained as monolayer cultures in Dulbecco's modified Eagle's medium (DMEM) supplemented with $10 \%$ FBS and antibiotics (100U/ml penicillin and $100 \mu \mathrm{g} / \mathrm{ml}$ streptomycin), under an atmosphere of $5 \% \mathrm{CO}_{2}$ at $37^{\circ} \mathrm{C}$. Cells were trypsinised when nearly confluent. 
112 Cells were seeded onto 12 -well plates, with $1 \mathrm{ml} /$ well at a density of $0.2 \times 10^{6}$ cells $/ \mathrm{ml}$,

113 and incubated with different concentrations of test compounds in complete DMEM

114 medium to test for possible direct cytotoxicity, genotoxicity, and for effects on induced

115 DNA oxidation, and for modulation of DNA repair. Stock solutions of UA and Lut were

116 prepared in dimethyl sulphoxide (DMSO) and aliquots kept at $-20^{\circ} \mathrm{C}$. The final

117 concentration of DMSO in medium was $<0.5 \%$ ).

\subsection{Cell toxicity assay}

120 The test compound's cytotoxicity was assayed in 12-multiwell culture plates seeded 121 with $0.2 \times 10^{6}$ cell /well. Twenty-four hours after plating, the medium was discarded 122 and fresh medium containing test compounds at different concentrations was added.

123 After $48 \mathrm{~h}$ of incubation with test compounds, cytotoxicity was evaluated by MTT test.

124 The number of viable cells in each well was estimated by the cell capacity for reduction

125 of MTT as described by [18]. The results were expressed as a percentage of cell

126 viability relative to control (cells without any test compound).

\subsection{Comet assay}

129 The alkaline version of the single cell gel electrophoresis assay was used to evaluate 130 DNA damage as previously described [19] with some modifications. Briefly, Caco-2 cells were trypsinized, washed, centrifuged, and the pellet suspended in low melting point agarose; about $2 \times 10^{4}$ cells were placed on a slide (pre-coated with $1 \%$ normal melting point agarose and dried), and covered with a coverslip. After $10 \mathrm{~min}$ at $4{ }^{\circ} \mathrm{C}$, the coverslips were removed and slides were placed in lysis solution $(2.5 \mathrm{M} \mathrm{NaCl}, 100 \mathrm{mM}$ $\mathrm{Na}_{2}$ EDTA, $10 \mathrm{mM}$ Tris Base, $\mathrm{pH} 10$ plus $1 \%$ Triton X-100) for $1 \mathrm{~h}$ at $4^{\circ} \mathrm{C}$. When oxidised bases were to be measured, after lysis slides were washed three times with buffer (40mM HEPES, 0.1M KCl, 0.5mM EDTA, 0.2mg/ml BSA, pH 8.0) and incubated with $30 \mu \mathrm{l}$ of formamidopyrimidine DNA glycosylase (FPG) in this buffer or with buffer only for $20 \mathrm{~min}$ at $37^{\circ} \mathrm{C}$. Slides were then placed in horizontal electrophoresis chamber with electrophoresis solution $(300 \mathrm{mM} \mathrm{NaOH}, 1 \mathrm{mM}$ $\mathrm{Na}_{2}$ EDTA, $\mathrm{pH}>13$ ) for $30 \mathrm{~min}$ at $4^{\circ} \mathrm{C}$ for the DNA to unwind before electrophoresis

142 was run for $30 \mathrm{~min}$ at $25 \mathrm{~V}$ and $\sim 300 \mathrm{~mA}$. After electrophoresis, slides were washed two

143 times with PBS and dried at room temperature. For analysis of the comet images, slides 
144 were stained with SYBR Gold solution for $30 \mathrm{~min}$ at $4^{\circ} \mathrm{C}$; after drying, slides were 145 analysed in a fluorescence microscope and Comet 4 analysis system (Perceptive

146 software) was used to calculate the parameter \% tail intensity. Generally, 100 randomly

147 selected cells are analyzed per sample.

2.5. Genotoxic effects of UA and Lut

150 Caco-2 cells were incubated for $24 \mathrm{~h}$ at $37^{\circ} \mathrm{C}$ with UA and Lut at different concentrations. Cells were collected by trypsinization and DNA damage (strand breaks,

$152 \mathrm{SBs}$ ) was evaluated by the alkaline version of the comet assay. Digestion with FPG

153 allowed detection of oxidized purines [20].

\subsection{Effects of UA and Lut on DNA oxidation.}

156 To evaluate protection against oxidative damage, Caco- 2 cells were preincubated with 5 and $10 \mu \mathrm{M}$ UA or 10 and $20 \mu \mathrm{M}$ Lut for $24 \mathrm{~h}$ (long period of incubation) or $2 \mathrm{~h}$ (short period of incubation) at $37^{\circ} \mathrm{C}$. Cells were washed with $\mathrm{PBS}$ and treated with $\mathrm{H}_{2} \mathrm{O}_{2}(75$ $\mu \mathrm{M}$ in PBS) for $5 \mathrm{~min}$ on ice to induce SBs, or with $1 \mu \mathrm{M}$ Ro (photosensitizer Ro19-

160 8022, prepared in PBS from a stock solution at $1 \mathrm{mM}$ in ethanol) plus visible light from

161 a $500 \mathrm{~W}$ tungsten-halogen source (1.5min on ice) at $33 \mathrm{~cm}$ to induce 8 -oxoGua. DNA 162 damage (SBs and 8-oxoGua) was evaluated by the comet assay without or with FPG, 163 respectively.

2.7. Effects of UA and Lut on cellular repair.

166 In the cellular repair assay two different treatment regimes were used: First, pre167 treatment with UA or Lut followed by exposure to $\mathrm{H}_{2} \mathrm{O}_{2}$ and recovery in fresh medium.

168 Caco-2 cells were preincubated with UA or Lut for $24 \mathrm{~h}$ at $37^{\circ} \mathrm{C}$. Cells were washed with 169 PBS and treated with $\mathrm{H}_{2} \mathrm{O}_{2}(75 \mu \mathrm{M})$ for 5 min on ice to induce SBs. The $\mathrm{H}_{2} \mathrm{O}_{2}$ was 170 removed and cells were washed with PBS and then incubated in fresh culture medium 171 for $0,10,30$ or $60 \mathrm{~min}$ at $37^{\circ} \mathrm{C}$. Thus we evaluated the effect of pre-incubation in UA or 172 Lut on the ability of cells to rejoin SBs [19]. In the second approach, to look for a 173 possible direct effect of UA or Lut on enzyme activity, $\mathrm{H}_{2} \mathrm{O}_{2}$ treatment was performed 174 before cells were incubated with the test compounds. Briefly, Caco-2 cells were treated 
with $\mathrm{H}_{2} \mathrm{O}_{2}(75 \mu \mathrm{M})$ for 5 min on ice to induce SBs. Cells were washed with PBS to

176 remove $\mathrm{H}_{2} \mathrm{O}_{2}$ and then incubated with UA or Lut for $0,10,30$ or $60 \mathrm{~min}$ at $37^{\circ} \mathrm{C}$.

177 Results were expressed as \% of repair DNA damage that was calculated using the

178 follow formula:

$179 \%$ of repair DNA damage $=\left(\mathrm{T}_{0}-\mathrm{T}_{30}\right) /\left(\mathrm{T}_{0}-\mathrm{C}_{30}\right) \times 100 ;$ where $\mathrm{T}_{0}$ represents DNA

180 damage before recovery period, $\mathrm{T}_{30}$ represents DNA damage after $30 \mathrm{~min}$ of recovery

181 and $\mathrm{C}_{30}$ represents DNA damage of the control after 30 min of recovery.

182

\subsection{Effects of UA and Lut on BER (in vitro assay)}

184 This assay measures the excision repair activity of an extract prepared from cells treated

185 with test compounds by providing the extract with a DNA substrate (agarose-embedded 186 nucleoids) containing specific damage [17]. In this case, the substrate DNA was from

187 cells previously exposed to Ro plus visible light to induce 8-oxoGua that is repaired by

188 BER, and was prepared as described by Gaivão et al. [21]. Incision at damage sites,

189 detected using the alkaline comet assay, indicates the capacity of glycosylase in the

190 extract to initiate BER.

\subsubsection{Cell extract preparation}

193 Extracts were prepared as described previously [17] with some modifications. Briefly,

194 for extract preparation, Caco-2 cells were incubated with $10 \mu \mathrm{M} \mathrm{UA}, 10 \mu \mathrm{M}$ Lut or $0.5 \%$

195 DMSO (control) for $24 \mathrm{~h}$ at $37^{\circ} \mathrm{C}$. Cells were washed with PBS, trypsinized and

196 resuspended in PBS. Cells were divided into aliquots of $1 \times 10^{6}$ cells in $1 \mathrm{ml}$ and after

197 centrifugation $\left(14000 \mathrm{~g} ; 5 \mathrm{~min}\right.$ at $\left.4^{\circ} \mathrm{C}\right)$ the dry pellets were frozen in liquid nitrogen and

198 stored at $-80^{\circ} \mathrm{C}$.

\subsubsection{Substrate preparation}

201 Substrates for BER assay were preparated as described previously [17]. Briefly, HeLa

202 cells cultivated in flasks, when near to confluence were treated with Ro plus visible

203 light (5 $\mathrm{min}$ at $33 \mathrm{~cm}$ on ice) to induce 8-oxoGua. Cells were washed with PBS,

204 trypsinised and resuspended in medium. Cells were centrifuged, the pellet resuspended

205 in freezing medium (DMEM medium supplemented with 20\% FBS and 10\% DMSO) 
and aliquots of $1 \times 10^{6}$ cells in $1 \mathrm{ml}$ frozen slowly and stored at $-80^{\circ} \mathrm{C}$. HeLa cells without

207 Ro treatment were also frozen in freezing medium and stored at $-80^{\circ} \mathrm{C}$.

\subsubsection{Substract incubation with cell extract}

210 On the day of the experiment, extracts were resuspended in $65 \mu 1$ of extraction buffer

211 (45mM Hepes, 0.4M KCl, 1mM EDTA, 0.1mM dithiothreitol and 10\% glycerol, $\mathrm{pH}$

212 7.8) plus Triton X-100 (0.25\%), mixed 5sec on vortex at top speed and incubated 5 min

213 on ice. After centrifugation $\left(\sim 14,000 \mathrm{xg}, 4^{\circ} \mathrm{C}, 5 \mathrm{~min}\right) 55 \mu \mathrm{l}$ of supernatant was removed

214 and mixed with $220 \mu \mathrm{l}$ of cold reaction buffer (40mM HEPES, $0.1 \mathrm{M} \mathrm{KCl}, 0.5 \mathrm{mM}$

215 EDTA and $0.2 \mathrm{mg} / \mathrm{ml}$ bovine serum albumin, $\mathrm{pH} 8$ ). Two gels per slide containing $2 \times 10^{4}$

216 substrate cells /gel (with or without treatment with Ro) were placed on slides pre-coated

217 with normal melting point agarose and lysed for $1 \mathrm{~h}$. Slides were washed three times

218 with reaction buffer and $30 \mu 1$ of extract was added to each gel and incubated $20 \mathrm{~min}$ at

$21937^{\circ} \mathrm{C}$ in a moist box. FPG and reaction buffer were included as positive and negative

220 controls, respectively. After incubation, slides were transferred immediately to alkaline

221 electrophoresis solution and the normal comet assay was run [17, 22.]

\subsection{Statistical analysis}

Results were expressed as mean \pm SEM at least 3 independent experiments.

Significant differences $(P<0.05)$ were evaluated by Student's t-test.

\section{Results}

\subsection{Cytotoxic effects of UA and Lut}

In order to choose the concentrations of UA and Lut that can be used in protective

230 studies, evaluations of test compounds' toxicity were done using MTT test. When Caco-

2312 cells were incubated for $48 \mathrm{~h}$, UA and Lut significantly decreased cell viability only at

232 concentrations higher than 50 and $100 \mu \mathrm{M}$, respectively (Fig. 1). For the follow

233 experiments non-cytotoxic concentrations of UA and Lut were used. 
236 The effects of UA and Lut on induction of SBs and oxidized bases were evaluated. For

237 this, Caco-2 cells were incubated with UA (5 and $10 \mu \mathrm{M})$ or Lut (10 and $20 \mu \mathrm{M})$ for $24 \mathrm{~h}$

238 at $37^{\circ} \mathrm{C}$ and DNA damage assessed by the comet assay with and without FPG treatment.

239 At tested concentrations UA and Lut did not induce either SBs or oxidized purines

240 (FPG-sensitive sites) (Fig.2).

\subsection{Effects of UA and Lut on oxidatively induced-DNA damage.}

243 To evaluate possible effects of UA or Lut on oxidatively induced-DNA damage, Caco-2

244 cells were incubated for $24 \mathrm{~h}$ (a long) or $2 \mathrm{~h}$ (a short) periods with the compounds before

245 treatment with $\mathrm{H}_{2} \mathrm{O}_{2}$ or Ro.

246 Both $5 \mu \mathrm{M}$ UA and $20 \mu \mathrm{M}$ Lut, with a long period of incubation, significantly decreased

247 DNA SBs induction by $\mathrm{H}_{2} \mathrm{O}_{2}$ (Fig.3A). With a short period of incubation (2h), the

248 effects of UA and Lut were even more pronounced (Fig.3B). The protective effects

249 were not dose-dependent.

250 In the assay with Ro plus light, Caco-2 cells were also pre-treated for a long or short

251 period with UA or Lut. With a long period of incubation, compounds at tested

252 concentrations did not protect DNA from damage induced by Ro (Fig.4A). With a short

253 incubation Lut significantly decreased oxidized DNA bases induced by Ro, while UA

$254(10 \mu \mathrm{M})$ showed a tendency to protect Caco-2 cells (Fig.4B).

\subsection{Effects of UA and Lut on repair ability.}

\subsubsection{Cellular repair assay}

258 The ability of Caco-2 cells to rejoin strand breaks induced by $\mathrm{H}_{2} \mathrm{O}_{2}$ was assessed by measuring damage remaining at different times of recovery (0, 10, 30 and $60 \mathrm{~min})$. SBs

260 decreased with the time of recovery and at $60 \mathrm{~min}$ the levels of SBs were similar to the

261 control (without $\mathrm{H}_{2} \mathrm{O}_{2}$ treatment) (data not shown). To assess effects of the test

262 compounds on the ability of Caco-2 cells to rejoin DNA strand breaks, two different

263 treatments were used. First, cells were treated with compounds for $24 \mathrm{~h}$ before $\mathrm{H}_{2} \mathrm{O}_{2}$

264 exposure and recovery in fresh medium for $30 \mathrm{~min}$ at $37^{\circ} \mathrm{C}$. For recovery time we chose

26530 min because it is within the linear phase of SB repair (Fig. 5A). Caco-2 cells treated

266 only with $\mathrm{H}_{2} \mathrm{O}_{2}$ (control cells), after 30 min of recovery had rejoined $\sim 50 \%$ of SBs. 
267 Cells pre-incubated with $5 \mu \mathrm{M}$ UA or $10 \mu \mathrm{M}$ Lut had rejoined $86 \%$ and $88 \%$

268 respectively, representing a relative increase in the extent of DNA rejoining of $65 \%$ and $26968 \%$ compared with the control cells, respectively. The highest concentrations of UA

270 and Lut show a tendency $(\mathrm{p} \leq 0.1)$ to increase the ability to rejoin SBs (Fig.5B).

271 In the second treatment, cells were incubated with test compounds for different times

272 after $\mathrm{H}_{2} \mathrm{O}_{2}$ exposure. No difference was found when cells were incubated with

273 compounds during the recovery period when compared with cells incubated with fresh

274 medium after $\mathrm{H}_{2} \mathrm{O}_{2}$ exposure (data not shown) indicating the absence of any direct

275 influence on repair enzymes.

\subsubsection{BER activity measured in vitro}

278

279

280

281

282

283

284

285

286

287

288

289

290

291

292

293

294

295

296

297

The ability of Caco-2 cells to repair oxidised bases by BER was measured by a modified comet assay, the in vitro BER assay. In this assay a DNA substrate containing specific damage, 8-oxoGua, induced by Ro plus visible light was incubated with an extract of Caco-2 cells (treated with UA or Lut for $24 \mathrm{~h}$ at $37^{\circ} \mathrm{C}$ ). Figure 6 shows, first, that substrate when treated with FPG (positive control) increased SBs detected by comet assay compared with substrate incubated only with reaction buffer (negative control). Second, extract from Caco-2 cells treated only with DMSO led to an increase in SBs in substrate DNA when compared with the negative control. This means that the extract from Caco-2 cells has BER activity. And third, extracts obtained from cells pre-treated with $10 \mu \mathrm{M}$ UA showed significantly increased excision repair activity, by $24 \%$ when compared with an extract of Caco-2 cells treated with DMSO, while repair activity was not significantly affected by pre-treatment with Lut. There was no increase in SBs when extracts were incubated with substrate without 8-oxoGua (data not shown), indicating that the increase of breaks observed for UA corresponds to 8-oxoguanine DNA glycosylase 1 (OGG1) enzyme activity and confirming the absence of nonspecific nucleases in cell extracts.

\section{Discussion}

The integrity of DNA is critically important for DNA replication and cell division. Oxidative DNA damage in addition to a defective DNA repair mechanisms are known to be associated with carcinogenesis [23, 24]. Dietary antioxidants have the possibility 
to prevent oxidation, but this requires that they are in proximity to the DNA in an active

300 form. Several authors have reported that a compound's lipophilicity is a determinant

301 characteristic for biological activity of the compounds. UA and Lut represent two

302 classes of phytochemicals with different chemical and biological properties. Lut has free

303 radical scavenging activity, whereas UA is virtually inactive as a free radical scavenger.

304 Both are, however, highly lipophilic [25-27]. We evaluated the effects of both

305 compounds, UA and Lut, against oxidative damage in Caco-2 cells at two levels: DNA

306 protection and DNA repair. In this work, we show that ursolic acid and luteolin not

307 only protect DNA from oxidative damage after a short period of pre-incubation but also

308 increase repair activity in Caco-2 cells.

309 Concerning DNA protection, after a short incubation period ( $2 \mathrm{~h}$ ) UA and Lut had a

310 strong protective effect against $\mathrm{H}_{2} \mathrm{O}_{2}$-induced DNA damage. After a long period of

311 incubation ( $24 \mathrm{~h}$ ) both compounds showed a protective effect, but the percentage

312 protection was smaller than with a short incubation period. In a previous paper, we

313 showed that UA had chemoprotective activity against $t$ BHP-induced DNA damage in

314 HepG2 cells [24]. Our results are in agreement with other reports that also show that

315 UA protects against $\mathrm{H}_{2} \mathrm{O}_{2}$-induced DNA damage [28,29] and decreased the level of

316 AZT (3'-azido-3'-dideoxythymidine)-induced SBs in Caco-2 and HepG2 cells [30]. The

317 protective effect of Lut against $\mathrm{H}_{2} \mathrm{O}_{2}$-mediated DNA SBs in Caco-2 cells is also in

318 agreement with results obtained with other cell lines [26,31-35].

319 Besides DNA SBs, 8-oxoGua is one of the most abundant forms of oxidative damage

320 and has been shown to cause $\mathrm{G}$ to $\mathrm{T}$ transversions. To evaluate effects on DNA

321 protection against 8-oxoGua formation, we exposed Caco-2 cells to Ro plus visible light

322 (to induce 8-oxoGua). Lut protected against Ro-induced DNA damage in Caco-2 after a

323 short period of pre-incubation while UA showed a similar tendency. However, this

324 protective effect was not observed with a long period of pre-incubation for either

325 compound. Moon et al. [36] reported that dietary antioxidants such as quercetin, rutin

326 and resveratrol as well as UA inhibit single strand breaks and 8-oxoGua in U937 cells

327 exposed to 3-morpholinosydnomine N-ethylcarbamide (SIN-1). The protective effects

328 of Lut against 8-oxoGua found in Caco-2 are in agreement with others authors. Cai et

329 al. [37] showed that Lut, quercetin and genistein decrease oxidative damage to DNA,

330 and among the test compounds, Lut had the most potent quenching effect on Fenton

331 reaction-induced 8-oxoGua formation. Also Min and Ebeler [38] showed that several 
332 flavonoids including Lut slightly inhibited 8-oxoGua formation in calf thymus DNA at

333 low, physiologically relevant concentrations.

334 Phytochemicals such as flavonoids and triterpenoids can act as antioxidants in cells by modulating the activity of enzymatic and non-enzymatic cellular antioxidants and

336 activating (phase I) enzymes and detoxifying (phaseII) enzymes involved in xenobiotic 337 metabolism $[24,39,40]$.

338 The protective effect of UA has been attributed to the ability of UA to increase levels of non-enzymatic antioxidants such as glutathione (GSH) and to increase the activity of antioxidant enzymes such as catalase (CAT), glutathione peroxidase (GPX) and superoxide dismutase (SOD) [29,41,42]. Martin-Aragon et al. [43] reported that UA restores hepatocyte antioxidant levels preventing carbon tetrachloride-induced liver damage. Also, Saravan et al. [44] showed that UA has a hepatoprotective effect against

344 chronic ethanol-mediated toxicity in rats. UA increased levels of circulatory

345 antioxidants such as reduced glutathione, ascorbic acid and alpha-tocopherol improving 346 the antioxidant status of alcoholic rats.

347 Németh et al. [45] reported that Lut and quercetin were incorporated in small intestinal 348 epithelial cells and located in the nuclei, decreasing 8-oxoGua formation. Lut has been 349 reported as able to modulate antioxidant status, increasing the activities of antioxidant 350 enzymes GPX, glutathione-S-transferase (GST), glutathione reductase (GR), SOD and 351 CAT or attenuating the decrease of antioxidant levels (e.g. GSH) induced by toxic 352 agents $[14,26,46]$.

353 In our study Lut and UA seem to exert effects through cellularly mediated mechanisms

354 that can be lost with time. Despite the differences of antiradical capacity between the 355 two compounds, both showed a strong protector effect against oxidation of DNA, 356 reinforcing the notions that cellularly mediated effects and the degree of hydrophobicity 357 and consequently uptake into the cell are important factors to be taken into account 358 when assessing the effectiveness of antioxidant protection.

359 DNA damage combined with defects in repairing oxidative damage to DNA has been 360 associated with a development of several diseases including cancer [47,48]. Cells have 361 multiple DNA repair pathways for specific classes of lesions that mitigate the 362 deleterious consequences of damage accumulation. Effects of natural compounds on 363 DNA repair are still poorly understood; some reports show that polyphenols such as 
364 curcumin and quercetin increase DNA repair activity [27,49]. To our knowledge, there

365 are no studies reporting the effects of UA and Lut on DNA repair activity in colon cells.

366 In our present study, $24 \mathrm{~h}$ of pre-treatment with UA or Lut increased the rate of

367 rejoining of strand breaks in Caco-2 cells after treatment with $\mathrm{H}_{2} \mathrm{O}_{2}$. However, when

368 cells were incubated with test compounds after $\mathrm{H}_{2} \mathrm{O}_{2}$-induced damage, no such effects

369 were observed. This suggests an effect of the compounds on induction of repair activity

370 not due to direct interactions between UA or Lut and the repair enzymes.

371 The major mechanism that cells use to repair oxidative damage lesions is the BER

372 pathway. Here, we have measured the incision activity of a cell extract from Caco-2

373 cells treated for $24 \mathrm{~h}$ with test compounds on a DNA substrate containing specific

374 damage (8-oxoGua), to evaluate induction of BER activity. For the first time we report

375 that UA, but not Lut, has a BER-inductive effect, increasing incision activity in Caco-2

376 cells. In accordance with our results, Silva et al. [34] did not find effects of Lut on BER

377 activity in neuronal cells. However, Leung et al. [50] found that Lut increased the

378 mRNA expression of DNA base excision repair enzymes, such as hOGG1 and apurinic

379 endonuclease in human lung carcinoma cells.

380 In summary, we demonstrated for the first time that UA and Lut not only protect DNA

381 from oxidative damage but also increase repair activity in Caco- 2 cells. These protective

382 effects of UA and Lut may contribute to their anti-carcinogenic effects. Modulation of

383 DNA repair by these compounds and other phytochemicals needs to be further explored.

384 In vivo studies in animals or humans, making use of functional biomarker assays such as

385 the comet assay can provide a better understanding of the potentially important impact

386 of phytochemicals on DNA repair pathways and cancer prevention.

387

388 Conflict of interest

389 There are no conflicts of interest to report.

391 Acknowledgements

392 Ramos AA is supported by the Foundation for Science and Technology, Portugal, grant

393 SFRH/BD/35672/2007. 
396 [1] J. Ferlay, P. Autier, M. Boniol, M. Heanue, M. Colombet, P. Boyle, Estimates of the cancer incidence and mortality in Europe in 2006, Ann. Oncol. 18 (2007) 581-592.

398 [2] T. Tsuzuki, Y. Nakatsu, Y. Nakabeppu, Significance of error-avoiding mechanisms for oxidative

399 DNA damage in carcinogenesis, Cancer Sci. 98 (2007) 465-470.

400 [3] C.L. Powell, J.A. Swenberg, I. Rusyn, Expression of base excision DNA repair genes as a biomarker 401 of oxidative DNA damage, Cancer Lett. 229 (2005) 1-11.

402 [4] T.K Hazra, A. Das, S. Das, S. Choudhury, Y.W. Kow, R. Roy, Oxidative DNA damage repair in 403 mammalian cells: a new perspective. DNA Repair (Amst). 6 (2007) 470-480.

404 [5] S. Rajamanickam, R. Agarwal, Natural products and colon cancer: current status and future prospects, 405 Drug Dev. Res. 69 (2008) 460-471.

406 [6] S. Klenow, F. Jahns, B.L. Pool-Zobel, M. Glei, Does an extract of carob (Ceratonia siliqua L.) have 407 chemopreventive potential related to oxidative stress and drug metabolism in human colon cells? J. Agric. 408 Food Chem. 57 (2009) 2999-3004.

409 [7] S. Kawanishi, S. Oikawa, M. Murata, Evaluation for safety of antioxidant chemopreventive agents, 410 Antioxid. Redox Signal. 7 (2005) 1728-1739.

411 [8] A.R. Amin, O. Kucuk, F.R. Khuri, D.M. Shin, Perspectives for cancer prevention with natural 412 compounds, J. Clin. Oncol. 27 (2009) 2712-2725.

413 [9] J. Liu, Pharmacology of oleanolic acid and ursolic acid, J. Ethnopharmacol. 49 (1995) 57-68.

414 [10] Z. Ovesná, A. Vachálková, K. Horváthová, D. Tóthová, Pentacyclic triterpenoic acids: new 415 chemoprotective compounds. Minireview, Neoplasma 51 (2004) 327-333.

416 [11] Y.H. Shih, Y.C. Chein, J.Y. Wang, Y.S. Fu,Ursolic acid protects hippocampal neurons against 417 kainate-induced excitotoxicity in rats, Neurosci. Lett. 362 (2004) 136-140.

418 [12] Y.Q. Meng, D. Liu, L.L. Cai, H. Chen, B. Cao, Y.Z.Wang, The synthesis of ursolic acid derivatives 419 with cytotoxic activity and the investigation of their preliminary mechanism of action, Bioorg. Med.

420 Chem. 17 (2009) 848-854.

421 [13] C.C. Su, G.W. Chen, C.C.Yeh, M.D. Yang, C.F. Hung, J.G. Chung, Luteolin induces N-acetylation 422 and DNA adduct of 2-aminofluorene accompanying $\mathrm{N}$-acetyltransferase activity and gene expression in 423 human bladder cancer T24 cell line, Anticancer Res. 23 (2003) 355-362.

424 [14] P. Ashokkumar, G. Sudhandiran, Protective role of luteolin on the status of lipid peroxidation and antioxidant defense against azoxymethane-induced experimental colon carcinogenesis, Biomed. Pharmacother. 62 (2008) 590-597.

427 [15] G. Seelinger, I. Merfort, U. Wölfle, C.M. Schempp, Anti-carcinogenic effects of the flavonoid 428 luteolin, Molecules 13 (2008) 2628-2651.

429 [16] M. López-Lázaro, Distribution and biological activities of the flavonoid luteolin. Mini Rev. Med. 430 Chem. 9 (2009) 31-59.

431 [17] A.R. Collins, M. Dusinská, E. Horváthová, E. Munro, M. Savio, R. Stětina, Inter-individual 432 differences in repair of DNA base oxidation, measured in vitro with the comet assay, Mutagenesis 16 433 (2001) 297-301.

434 [18] J.P. Silva, F.M. Areias, F.M. Proença, O.P. Coutinho, Oxidative stress protection by newly synthesized nitrogen compounds with pharmacological potential, Life Sci. 78 (2006) 1256-1267.

436 [19] A.R. Collins, The comet assay for DNA damage and repair: principles, applications, and limitations, 437 Mol. Biotechnol. 26 (2004) 249-261

438 [20] M. Dusinská and A. R. Collins, Detection of oxidised purines and UV-induced photoproducts in 439 DNA of single cells, by inclusion of lesion-specific enzymes in the comet assay, Altern. Lab. Animals 24 440 (1996) 405-411.

441 [21] I. Gaivão, A. Piasek, A. Brevik, S. Shaposhnikov, A.R. Collins, Comet assay-based methods for 442 measuring DNA repair in vitro; estimates of inter- and intra-individual variation, Cell Biol. Toxicol. 25 443 (2009) 45-52. 
[22] Y. Lorenzo, A. Azqueta, L. Luna, F. Bonilla, G. Domínguez, A.R. Collins, The carotenoid betacryptoxanthin stimulates the repair of DNA oxidation in addition to acting as an antioxidant in human cells, Carcinogenesis, 30 (2009) 308-314.

[23] R. Olinski, D. Gackowski, M. Foksinski, R. Rozalski, K. Roszkowski, P. Jaruga, Oxidative DNA damage: assessment of the role in carcinogenesis, atherosclerosis, and acquired immunodeficiency syndrome, Free Radic. Biol. Med. 33 (2002) 192-200.

[24] L.R. Ferguson, M. Philpott, N. Karunasinghe, Dietary cancer and prevention using antimutagens, Toxicology 198 (2004) 147-159.

[25] A. H. Lo, Y.C. Liang, S.Y. Lin-Shiau, C.T. Ho, J.K. Lin, Carnosol, an antioxidant in rosemary, supresses inducible nitric oxide synthase through down-regulating nuclear factor-kB in mouse macrophages, Carcinogenesis 23 (2002) 983-991.

[26] C.F. Lima, M. Fernandes-Ferreira, C. Pereira-Wilson, Phenolic compounds protect HepG2 cells from oxidative damage: relevance of glutathione levels, Life Sci. 79 (2006) 2056-2068.

[27] A.A. Ramos, C.F. Lima, M.L. Pereira, M. Fernandes-Ferreira, C. Pereira-Wilson, Antigenotoxic effects of quercetin, rutin and ursolic acid on HepG2 cells, Toxicol. Lett. 177 (2008) 66-73.

[28] Z. Ovesná, K. Kozics, D. Slamenová, Protective effects of ursolic acid and oleanolic acid in leukemic cells, Mutat. Res. 600 (2006) 131-137.

[29] H.H. Yu, J.M. Hur, S.J. Seo, H.D. Moon, H.J. Kim, R.K. Park, Y.O. You, Protective effect of ursolic acid from Cornus officinalis on the hydrogen peroxide-induced damage of HEI-OC1 auditory cells, Am. J. Chin. Med. 37 (2009) 735-746.

[30] D. Slamenová, E. Horváthová, M. Bartková, Z. Krajcovicová, J. Lábaj, B. Kosíková, I. Masterová, Reduction of DNA-damaging effects of anti-HIV drug 3'-azido-3'-dideoxythymidine on human cells by ursolic acid and lignin biopolymer, Neoplasma 53 (2006) 485-491.

467 [31] M. Noroozi, W.J. Angerson, M.E. Lean, Effects of flavonoids and vitamin C on oxidative DNA 468 damage to human lymphocytes, Am. J. Clin. Nutr. 67 (1998) 1210-1218.

469 [32] K. Horvathova, L. Novotny, A. Vachalkova, The free radical scavenging activity of four flavonoids 470 determined by the comet assay, Neoplasma 50 (2003) 291-295.

[33] K. Horváthová, L. Novotný, D. Tóthová, A. Vachálková, Determination of free radical scavenging activity of quercetin, rutin, luteolin and apigenin in $\mathrm{H} 2 \mathrm{O} 2$-treated human ML cells K562, Neoplasma 51

473 (2004) 395-399.

[34] J.P. Silva, A.C. Gomes, O.P. Coutinho, Oxidative DNA damage protection and repair by polyphenolic compounds in PC12 cells, Eur. J. Pharmacol. 601 (2008) 50-60.

[35] S. Kilani-Jaziri, A. Neffati, I. Limem, J. Boubaker, I. Skandrani, M.B. Sghair, I. Bouhlel, W. Bhouri, A.M. Mariotte, K. Ghedira, M.G. Dijoux Franca, L. Chekir-Ghedira, Relationship correlation of antioxidant and antiproliferative capacity of Cyperus rotundus products towards K562 erythroleukemia cells, Chem. Biol. Interact. 181 (2009) 85-94.

480 [36] H.K. Moon, E.S. Yang, J.W. Park, Protection of peroxynitrite-induced DNA damage by dietary 481 antioxidants, Arch. Pharm. Res. 29 (2006) 213-217.

482 [37] Q. Cai, R.O. Rahn, R. Zhang, Dietary flavonoids, quercetin, luteolin and genistein, reduce oxidative 483 DNA damage and lipid peroxidation and quench free radicals, Cancer Lett. 119 (1997) 99-107.

484 [38] K. Min, S.E. Ebeler, Flavonoid effects on DNA oxidation at low concentrations relevant to 485 physiological levels, Food Chem. Toxicol. 46 (2008) 96-104.

486 [39] J.A. Ross, C.M. Kasum, Dietary flavonoids: bioavailability, metabolic effects, and safety, Annu. 487 Rev. Nutr. 22 (2002) 19-34.

488 [40] C. Chen, A.N. Kong, Dietary chemopreventive compounds and ARE/EpRE signaling, Free Radic. 489 Biol. Med. 36 (2004) 1505-1516.

490 [41] J. Lu, Y.L. Zheng, D.M. Wu, L. Luo, D.X. Sun, Q. Shan, Ursolic acid ameliorates cognition deficits 491 and attenuates oxidative damage in the brain of senescent mice induced by D-galactose, Biochem.

492 Pharmacol. 74 (2007) 1078-1090. 
493 [42] S.J. Tsai, M.C. Yin, Antioxidative and anti-inflammatory protection of oleanolic acid and ursolic 494 acid in PC12 cells, J. Food Sci. 73 (2008) 174-178.

495 [43] S. Martin-Aragón, B. de las Heras, M.I. Sanchez-Reus, J. Benedi, Pharmacological modification of 496 endogenous antioxidant enzymes by ursolic acid on tetrachloride-induced liver damage in rats and 497 primary cultures of rat hepatocytes, Exp. Toxicol. Pathol. 53 (2001) 199-206.

498 [44] R. Saravanan, P. Viswanathan, K.V. Pugalendi, Protective effect of ursolic acid on ethanol-mediated 499 experimental liver damage in rats, Life Sci.78 (2006) 713-718.

500 [45] K. Németh, G.W. Plumb, J.G. Berrin, N. Juge, R. Jacob, H.Y. Naim, G. Williamson, D.M. Swallow, 501 P.A. Kroon, Deglycosylation by small intestinal epithelial cell beta-glucosidases is a critical step in the 502 absorption and metabolism of dietary flavonoid glycosides in humans, Eur. J. Nutr. 42 (2003) 29-42.

503 [46] V. Manju, N. Nalini, Chemopreventive potential of luteolin during colon carcinogenesis induced by 504 1,2-dimethylhydrazine, Ital. J. Biochem. 5 (2005) 268-275.

505 [47] S. Loft, P. Møller, Oxidative DNA damage and human cancer: need for cohort studies, Antioxid. 506 Redox Signal. 8 (2006) 1021-1031.

507 [48] S. Mena, A. Ortega, J.M. Estrela, Oxidative stress in environmental-induced carcinogenesis, Mutat. 508 Res. 674 (2009) 36-44.

509 [49] S. Mukherjee, M. Roy, S. Dey, R.K. Bhattacharya, A Mechanistic Approach for Modulation of 510 Arsenic Toxicity in Human Lymphocytes by Curcumin, an Active Constituent of Medicinal Herb 511 Curcuma longa Linn, J. Clin. Biochem. Nutr. 41 (2007) 32-42.

512 [50] H.W. Leung, C.H. Wu, C.H. Lin, H.Z. Lee, Luteolin induced DNA damage leading to human lung 513 squamous carcinoma CH27 cell apoptosis, Eur. J. Pharmacol. 508 (2005) 77-83. 


\section{Figure legends}

Figure 1 - Effects of UA and Lut on cellular viability (as \% of control) of caco-2 cells as measured by MTT test. Results are expressed as mean \pm SEM, of at least three independent experiments.

Figure 2 - DNA damage (SBs and FPG-sensitive sites) in Caco-2 cells treated for $24 \mathrm{~h}$ with UA and Lut. Results are expressed as mean \pm SEM, of at least three independent experiments.

Figure 3 - Effects of $24 \mathrm{~h}(\mathrm{~A})$ or $2 \mathrm{~h}(\mathrm{~B})$ of treatment with UA or Lut on DNA damage induced by $75 \mu \mathrm{M} \mathrm{H}_{2} \mathrm{O}_{2}$ (5 min, on ice) in Caco- 2 cells. Results are expressed as mean \pm SEM, of at least three independent experiments.

Figure 4 - Effects of $24 \mathrm{~h}(\mathrm{~A})$ or $2 \mathrm{~h}(\mathrm{~B})$ of treatment with UA or Lut on DNA damage induced by $1 \mu \mathrm{M}$ Ro19-8022 plus light (1.5min, on ice) in Caco- 2 cells. Results are expressed as mean \pm SEM, of at least three independent experiments.

Figure 5 - Kinetic of SBs rejoining (A); and extent of repair of $\mathrm{H}_{2} \mathrm{O}_{2}$-induced damage in Caco-2 cells after preincubation with UA or Lut (B). Results are expressed as mean \pm SEM, of at least three independent experiments.

Figure 6 - In vitro DNA repair: incision by extracts from Caco-2 cells pre-incubated with $10 \mu \mathrm{M}$ of UA and Lut. Extracts were incubated for 20min with gel-embedded nucleoid DNA containing 8-oxoGua lesions. Results are expressed as mean \pm SEM, of four independent experiments. 
Figure 1

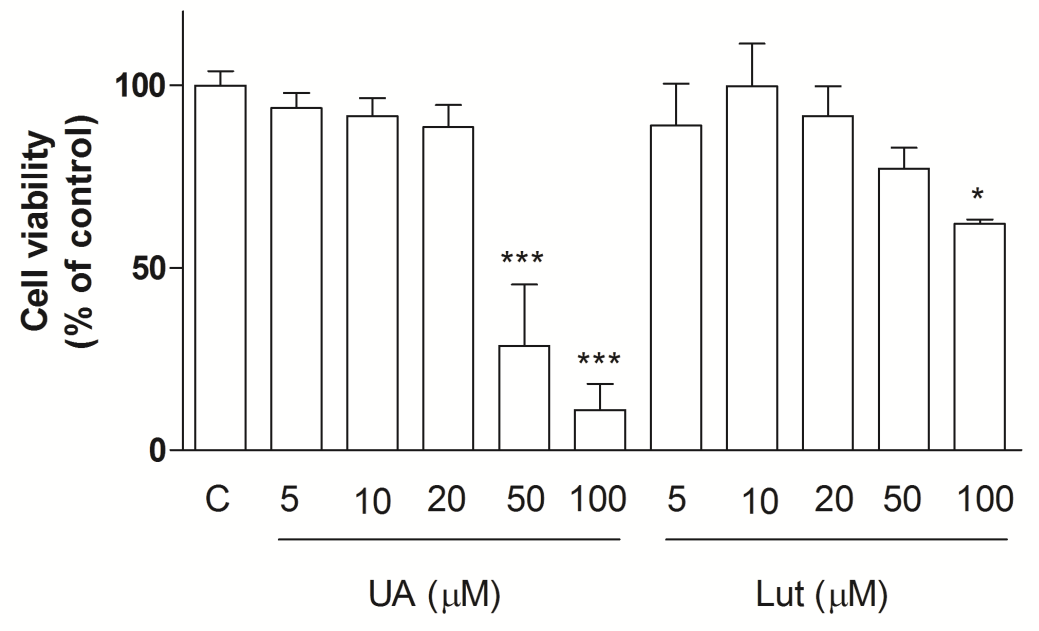


Figure 2

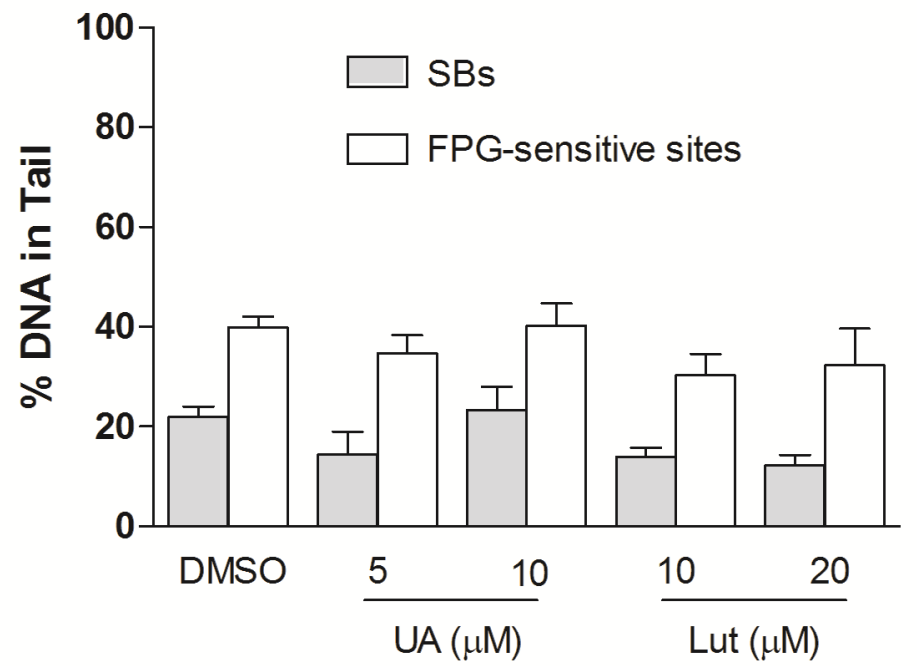


Figure 3

(A)

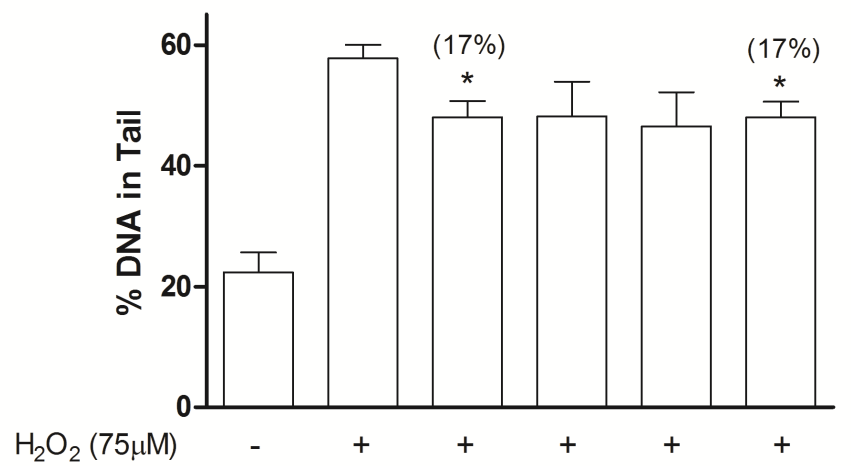

24h of preincubation DMSO DMSO $\frac{5 \quad 10}{\mathrm{UA}(\mu \mathrm{M})} \quad \frac{10 \quad 20}{\text { Lut }(\mu \mathrm{M})}$

(B)

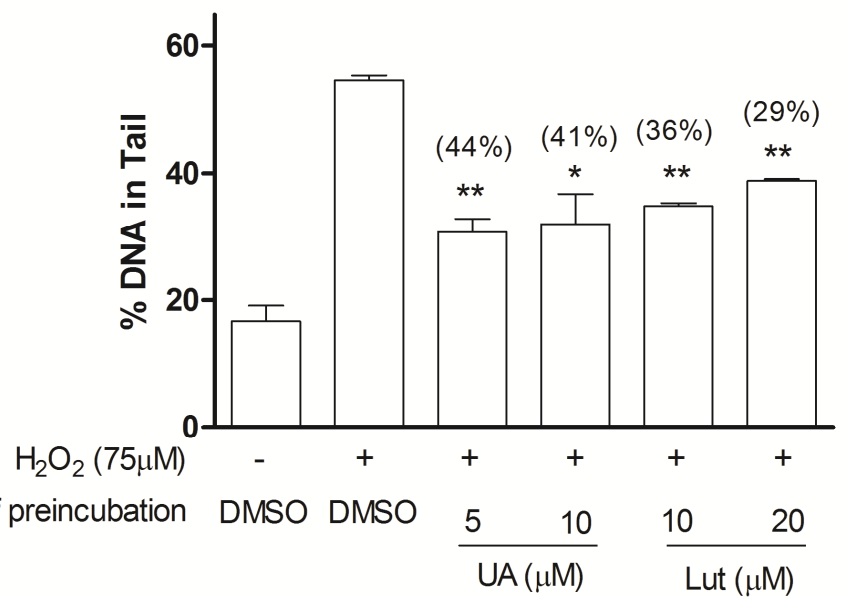


Figure 4

(A)

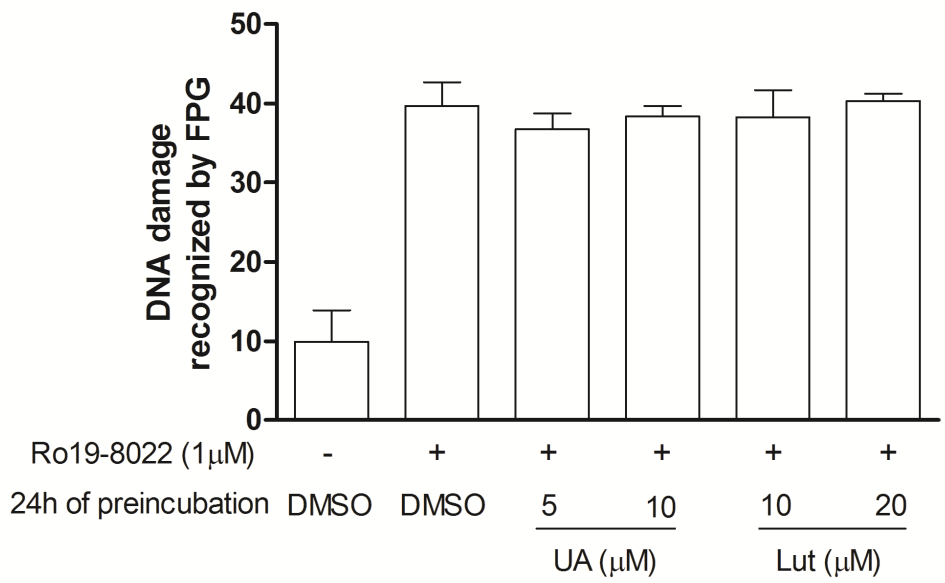

(B)

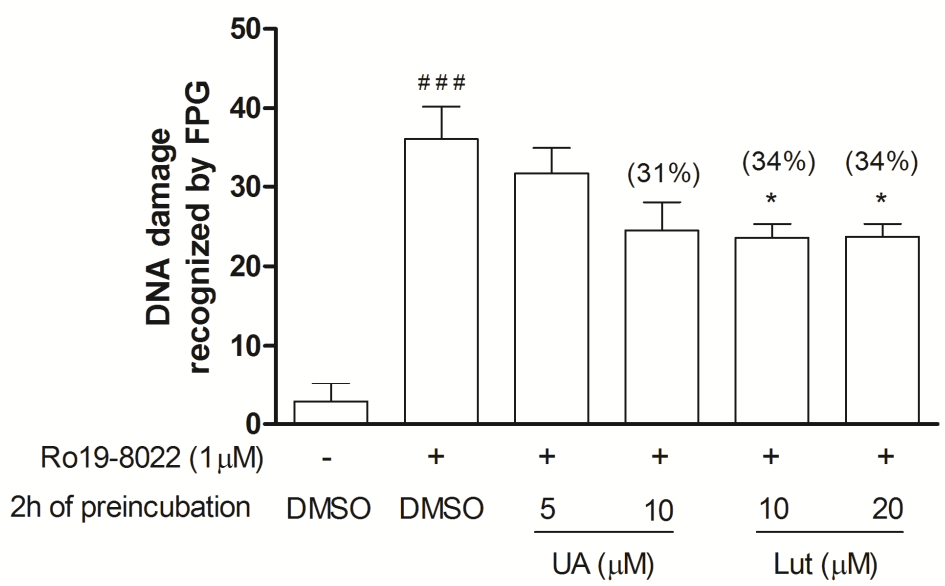


Figure 5

(A)

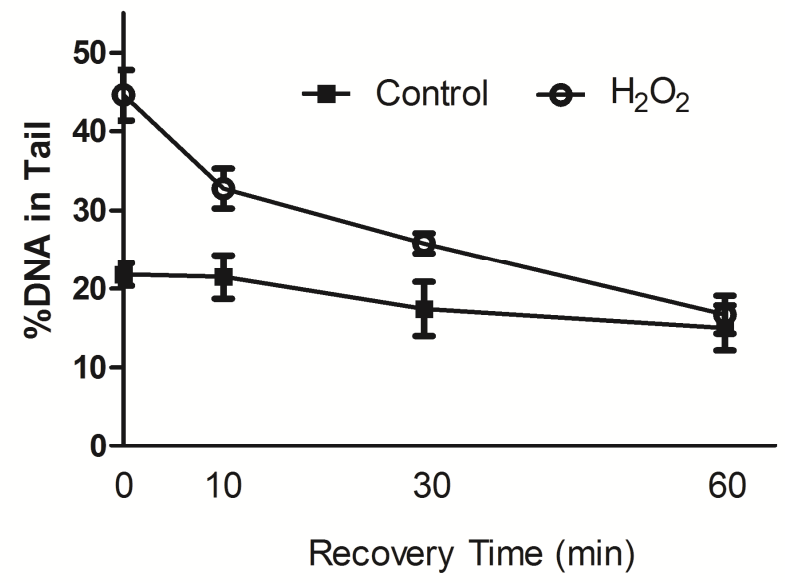

(B)

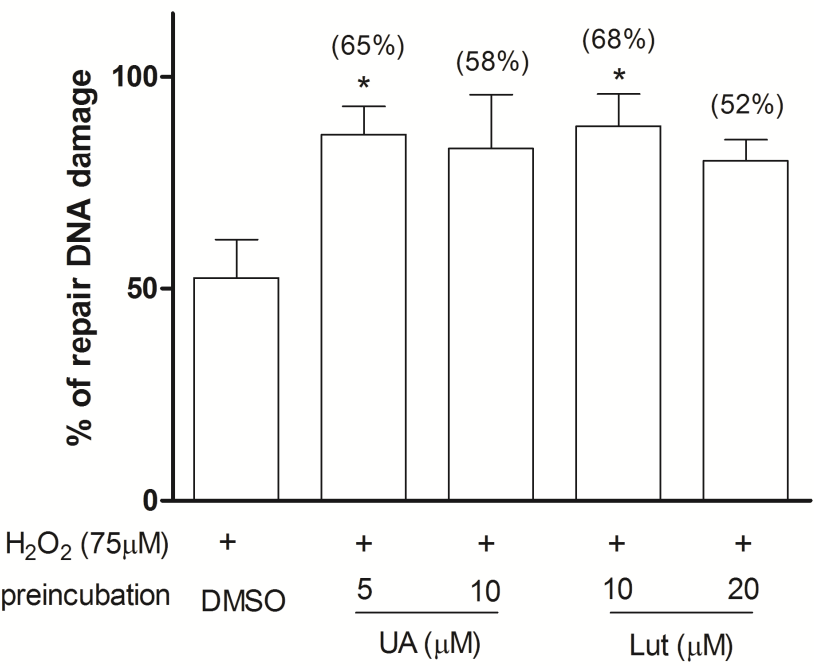


Figure 6

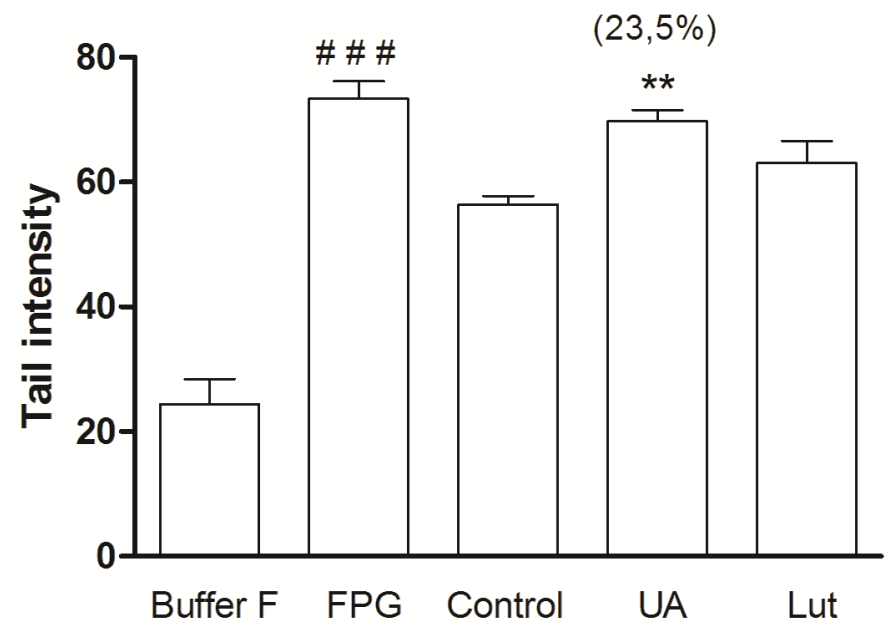

